\title{
Training the next generation of global health experts: experiences and recommendations from Pacific Rim universities
}

\author{
Mellissa Withers ${ }^{1 *}$, David Press ${ }^{1}$, Heather Wipfli ${ }^{1}$, Judith McCool $^{2}$, Chang-Chuan Chan ${ }^{3}$, Masamine Jimba ${ }^{4}$, \\ Christopher Tremewan ${ }^{5}$ and Jonathan Samet ${ }^{1}$
}

\begin{abstract}
Background: Finding solutions to global health problems will require a highly-trained, inter-disciplinary workforce. Global health education and research can potentially have long-range impact in addressing the global burden of disease and protecting and improving the health of the global population.

Methods: We conducted an online survey of twelve higher education institutions in the Pacific Rim that spanned the period 2005-2011. Program administrators provided data on program concentrations, student enrollment and student funding opportunities for 41 public health programs, including those specific to global health.

Results: The Master of Public Health (MPH) was the most common degree offered. A growing demand for global health education was evident. Enrollment in global health programs increased over three-fold between 2005-2011. Very few institutions had specific global health programs or offered training to undergraduates. Funding for student scholarships was also lacking.

Conclusions: The growing demand for global health education suggests that universities in the Pacific Rim should increase educational and training opportunities in this field. Schools of medicine may not be fully equipped to teach global health-related courses and to mentor students who are interested in global health. Increasing the number of dedicated global health research and training institutions in the Pacific Rim can contribute to building capacity in the region. Faculty from different departments and disciplines should be engaged to provide multi-disciplinary global health educational opportunities for undergraduate and graduate students. New, innovative ways to collaborate in education, such as distance education, can also help universities offer a wider range of global health-related courses. Additional funding of global health is also required.
\end{abstract}

Keywords: Global health education, Training, Pacific Rim, Global health degrees, MPH, Academic programs

\section{Background}

Increasingly, we are recognizing and responding to our global interdependence and collective exposure to transnational threats to health, as well as appreciating the relevance of global forces such as trade policy, migration, cooperation and governance $[1,2]$. The solutions to

\footnotetext{
* Correspondence: mwithers@usc.edu

'Department of Preventive Medicine, University of Southern California, Keck School of Medicine, 2001 N Soto Street SSB 318G, Los Angeles, CA 90064, USA

Full list of author information is available at the end of the article
}

current and future global health problems will require a highly-trained, inter-disciplinary global health workforce from the public and private sectors, non-governmental organizations and governments. Successful efforts to address emerging global health challenges will require the coordination of global health education, surveillance, research and service. However, many scholars have highlighted the lack of a sufficient workforce of trained global health professionals that will be able to accomplish these tasks [1-8]. 
Koplan et al. define global health as "the term applied to a rapidly growing area of research, training, and application of public health on a global scale" and point out that global health expertise requires not only public health training, but also additional competencies in topics such as global governance, cultural sensitivity, global disease trends, and global development, among others [9]. Although global health inherently has unbounded scope, its priorities are governed not only by global influences but by regional factors. The economies of the Pacific Rim, the lands around the edges of the Pacific Ocean, are pivotal in terms of their contributions to the global burden of disease [10]. More than 40 economies belong to this diverse region, representing Asia, Australia and Oceania, and the Americas. Key health issues facing the region include climate change, natural disasters, environmental degradation, the rise of noncommunicable diseases, and the threat of emerging and re-emerging diseases, such as SARS and tuberculosis. The health of Pacific Rim populations is challenged by some common issues, including fast-paced economic growth and industrialization, demographic changes, particularly aging, and rapid and extensive urbanization. The various health systems, while in differing phases of development, in some cases are struggling to provide equitable and fair health care for all, especially given the market-driven approaches and wide economic and health disparities.

Global health education and research can potentially have long-range impact in addressing the global burden of disease and protecting and improving the health of the global population. Many universities, institutes and associations around the world now offer global health training programs and numerous descriptions of such programs in the United States have been offered in the literature by such institutions as Boston University, University of California at San Francisco and Emory University [11-23]. Generally, such programs aim to provide students with opportunities to gain hands-on experience working in developing economies, improve core competencies, and gain increased awareness of the health challenges faced by populations around the world $[24,25]$. Most of these programs are housed within a larger health or public health program that is not focused specifically on global health. Furthermore, many of these global health experiences are short in duration, and offer limited experiences and exposure to the complex and often highly political and economic drivers of global health inequities. For example, Lencucha and Mohindra [26] examined global health courses at universities in Canada and the U.S. through a web search and found 67 courses were offered at 31 universities in the 2008-2009 academic year. They called for a more interdisciplinary training outside of traditional health science disciplines and highlighted the difficulty of including the breadth of issues pertaining to global health in a single course [26]. Several other scholars including Ackerly et al. [2], Merson et al. [23] and Drain et al. [24] have also called for a more comprehensive and ethical approach to global health training.

Here we present an analysis of the educational and training programs related to public health, focusing on global health, offered by numerous academic institutions in the Pacific Rim. We highlight recent trends in the increasing demand for global health education. We discuss the role played by academic institutions in the Pacific Rim in providing educational opportunities in global health and make recommendations on how universities can be better equipped to meet the demand for future global health leaders.

\section{Background on APRU}

The Association of Pacific Rim Universities (APRU) is an international consortium of 45 prestigious research universities in the Pacific Rim, representing 16 economies, 130,000 faculty members and more than two million students. The APRU Global Health Program was launched in 2007-08. The Program's activities in research, training, and service around the global illustrate the diverse dimensions of global health. The members are faculty who are actively engaged in global health research and education. A main purpose of the program is to foster further discussion on global health in a regional context, as our institutions respond to global and regional needs for capacity building. One key element is global health education and training, which takes place at the undergraduate, graduate and post-graduate levels across the institutions. The main objective of this study is to investigate the practices in educating and training the next generation of global health professionals in the Pacific Rim.

\section{Methods}

We conducted an online survey of APRU member and partner institutions in 2012. An invitation was sent out through the APRU listserv and by private email invitation. One administrator from each university's admissions office was asked to complete the written survey regarding the post-graduate public health programs that were offered and which were specific to global health. The survey was composed of three sections. Section 1 related to global health programs. Six questions were included, such as "What programs specific to global health do you offer?" and "Do you offer any online global health-related courses? Section 2 included fifty questions related to student enrollment in each of the programs. Questions included "How many students are enrolled in this program?" and "How many foreign students are 
enrolled in this program?" Section 3 contained eight questions focused on funding, such as "What percentage of students receive grants?" and "Are university scholarships available to your students?"

A public health program was defined as any general degree program degree or certificate program relating to public health, while a global health program was defined broadly as any program associated with an international or a global focus (including a degree program or a global health track within another degree program), regardless of the actual name of the program. In order to track trends, the survey asked about two time points: 2005 and 2011.

\section{Results}

Twelve universities from Australia, Chinese Taipei, Hong Kong, Indonesia, Japan, New Zealand, Singapore, the United States, and Vietnam ${ }^{1}$ provided programmatic and student data on 41 postgraduate programs in public health, including five institutions offering postgraduate programs specific to global health.

\section{The programs}

A rapidly growing demand for post-graduate public health education was evident from our findings. Over two-thirds of the academic programs surveyed were created after 1990, with the greatest number of new programs in the previous five years. As seen in Table 1, the Masters of Public Health (MPH) Program was the most common academic program offered across institutions (100\%), followed by the Doctor of Philosophy $(\mathrm{PhD})$ or another Doctoral Program (91.7\%), and the Masters of Science (MS) Program (58.2 \%). Aside from the most common degrees of $\mathrm{MPH}, \mathrm{PhD}$, and $\mathrm{DrPH}$, some universities offered degrees specific to global health, such as a Master of International Public Health, and several schools offered graduate diplomas or graduate certificate programs in global health. Programs were mainly housed within schools of public health but some universities housed their programs within the school of medicine or, in one case, the school of public policy. Of the 12 universities surveyed, only four offered distancelearning courses in public health and only five offered the opportunity for undergraduates to take any courses in public health.

\section{The students}

As seen in Table 2, the overall student enrollment in post-graduate public health programs increased approximately $21 \%$ from 2005 to 2011 . The highest percentage change increases were observed within the global health programs, which had an increased enrollment of $351 \%$. The slowest growth during that same time period was found within doctoral programs (6\%). In terms of student demographics, the majority of students being trained in each academic program in 2005 were female, and this imbalance became even more pronounced between 2005-2011, when more females enrolled in Doctorate, MS and Global Health programs. For example, in 2011, $77 \%$ of postgraduate global health students were female. MPH students accounted for the biggest proportion of student body among all degrees.

An increasing flow of international students across universities was also observed. Between 2005 and 2011, the number of international students enrolled increased $40 \%$ (from $n=727$ to $n=1014$ ) in general public health programs and $285 \%$ (from $n=39$ to $n=150$ ) in global health programs specifically. For both time periods, at

Table 1 Summary of APRU academic programs

\begin{tabular}{|c|c|c|c|c|c|c|c|c|}
\hline University Name & MPH program & MS program & $\begin{array}{l}\text { PhD or doctoral } \\
\text { program }\end{array}$ & $\begin{array}{l}\text { Certificate } \\
\text { training } \\
\text { program }\end{array}$ & Other & $\begin{array}{l}\text { Postgrad global } \\
\text { health specific } \\
\text { program }\end{array}$ & Online courses & $\begin{array}{l}\text { Under grad } \\
\text { global health } \\
\text { classes }\end{array}$ \\
\hline Chinese University of Hong Kong & Yes & Yes & Yes & No & No & No & No & Yes \\
\hline Hanoi School of Public Health & Yes & No & Yes & Yes & Yes & No & No & No \\
\hline John Hopkins University & Yes & Yes & Yes & Yes & No & Yes & Yes & Yes \\
\hline National Taiwan University & Yes & Yes & Yes & Yes & No & No & No & Yes \\
\hline Seoul National University & Yes & No & Yes & No & No & No & Yes & No \\
\hline Singapore National University & Yes & No & Yes & No & Yes & No & No & No \\
\hline University of Auckland & Yes & No & No & No & Yes & Yes & No & No \\
\hline University of Indonesia & Yes & No & Yes & Yes & No & No & Yes & Yes \\
\hline University of Malaya & Yes & Yes & Yes & Yes & Yes & No & No & No \\
\hline University of Southern California & Yes & Yes & Yes & No & No & Yes & No & Yes \\
\hline University of Sydney & Yes & Yes & Yes & Yes & Yes & Yes & Yes & No \\
\hline University of Tokyo & Yes & Yes & Yes & No & No & Yes & No & Yes \\
\hline Total & 12 & 7 & 11 & 6 & 5 & 5 & 4 & 6 \\
\hline
\end{tabular}


Table 2 Frequency distribution and percentage change of student characteristics aggregated across APRU institutions from 2005 to 2011, by academic program

\begin{tabular}{|c|c|c|c|c|c|c|c|c|c|c|c|c|c|c|c|}
\hline & \multicolumn{3}{|c|}{ Total $^{a}$} & \multicolumn{3}{|l|}{$\mathrm{MPH}$} & \multicolumn{3}{|c|}{ Doctorate } & \multicolumn{3}{|l|}{ MS } & \multicolumn{3}{|c|}{ Global health } \\
\hline & 2005 & 2011 & (\%chg) & 2005 & 2011 & (\%chg) & 2005 & 2011 & $\overline{\text { (\%chg) }}$ & 2005 & 2011 & $\overline{(\% c h g)}$ & 2005 & 2011 & $\overline{\text { (\%chg) }}$ \\
\hline Student enrollment & 3314 & 4009 & $21.0 \%$ & 1504 & 1874 & $24.6 \%$ & 998 & 1055 & $5.7 \%$ & 704 & 944 & $34.1 \%$ & 109 & 491 & $350.5 \%$ \\
\hline \multicolumn{16}{|l|}{ Sex } \\
\hline Female & 2202 & 2760 & $25.3 \%$ & 1030 & 1266 & $22.9 \%$ & 631 & 715 & $13.3 \%$ & 459 & 646 & $40.7 \%$ & 83 & 377 & $354.2 \%$ \\
\hline Male & 1112 & 1249 & $12.3 \%$ & 474 & 608 & $28.3 \%$ & 367 & 340 & $-7.4 \%$ & 245 & 298 & $21.6 \%$ & 26 & 114 & $338.5 \%$ \\
\hline \multicolumn{16}{|l|}{ Student status } \\
\hline International & 727 & 1014 & $39.5 \%$ & 420 & 596 & $41.9 \%$ & 207 & 231 & $11.6 \%$ & 61 & 127 & $108.2 \%$ & 39 & 150 & $284.6 \%$ \\
\hline Domestic & 2587 & 2995 & $15.8 \%$ & 1084 & 1278 & $17.9 \%$ & 791 & 824 & $4.2 \%$ & 643 & 817 & $27.1 \%$ & 70 & 341 & $387.1 \%$ \\
\hline \multicolumn{16}{|l|}{ Enrollment status } \\
\hline Full-time & 2473 & 2974 & $20.3 \%$ & 938 & 1058 & $12.8 \%$ & 832 & 931 & $11.9 \%$ & 638 & 887 & $39.0 \%$ & 66 & 361 & $447.0 \%$ \\
\hline Part-time & 841 & 1035 & $23.1 \%$ & 566 & 816 & $44.2 \%$ & 166 & 124 & $-25.3 \%$ & 66 & 57 & $-13.6 \%$ & 43 & 130 & $202.3 \%$ \\
\hline \multicolumn{16}{|l|}{ Physician (MD) status } \\
\hline Non-MDs & $\neq$ & & & 1114 & 1381 & $24.0 \%$ & $\neq$ & & & $\neq$ & & & $\neq$ & & \\
\hline MDs & & & & 390 & 493 & $26.4 \%$ & & & & & & & & & \\
\hline
\end{tabular}

${ }^{a}$ Column totals do not sum to $100 \%$ due to overlapping Global Health programs; Total student enrollment reflects sum of collected fields

Total for sub-categories reflects imputation based on the overall proportion of collected fields

${ }^{b}$ Derived based on proportion of females in each program. Missing data fields were imputed based on the overall proportion from the programs with complete data; $<1 \%$ of students were imputed

₹ Missing data for two or more Universities

least one in five students enrolled in MPH, Doctorate and Global Health Programs were international students. Proportional increases in international student matriculation outpaced those of domestic students from 20052011 in all programs except those specific to global health, in which an increase of $387.1 \%$ was found in domestic student matriculation.

\section{Funding}

Only one-half of universities offered scholarships for students. Almost every school said that national grants were available to students. However, one-half of universities reported that only a small minority of their students (1-25\%) received such grants. All of the universities reported little to no growth with regard to funding for students between 2005 and 2011.

\section{Discussion}

Global health education is becoming increasingly visible and the proliferation of new programs in the region shows that interest and participation in global health education specifically has accelerated in recent years. Merson and Chapman Page attribute this growth in the United States to three factors, including greater emphasis on internationalization in higher education, heightened public visibility of the global health agenda, and the expansion of new resources and opportunities for universities and students [27]. This trend has also been emphasized in the literature by Merson [23], Drain et al. [24] and Crump and Sugarman [25].
Our findings suggest that the growing demand for global health education and training programs is likely to continue. A preference for practice-based degrees, such as the $\mathrm{MPH}$, over the traditional research $\mathrm{PhD}$ degree was evident in our study. However, very few schools had established dedicated departments, or centers, of global health and very few offered undergraduate courses in global health. However, our results show that global health programs can be included in a wide variety of disciplines and housed in many different types of schools (e.g., medical, public health, nursing), which reflects the trend towards a more multidisciplinary global health field [6].

Here, we offer four major recommendations on providing global health education and training based on our collective experiences in training and educating students in this field, considering the special challenges that universities without schools of public health may face. First, the proliferation and the diversity of global health education programs in the Pacific Rim suggest that universities should meet the growing demand for global health education by offering more programs and degrees focused specifically on global health. Increasing the number of dedicated global health research institutions in the Pacific Rim could contribute to building capacity in the region. We found that very few schools in our study had established dedicated departments, or centers of global health. Many public health-related degrees were offered in schools of medicine, which may not be 
equipped to teach global health-related courses. One important challenge is the lack of teaching capacity in public health in general and global health in particular, especially in the smaller programs. Faculty may not be prepared to teach the diversity of topics required in global health education. Furthermore, schools of medicine may not have enough faculty members equipped to mentor students who are interested in global health.

Combined degree programs with a global health track, concentration or specialization, such as $\mathrm{MD} /$ $\mathrm{PhD}$ and MD/MPH programs, could help meet the demand for global health training in multidisciplinary programs. Institutions that do not have schools of public health should consider incorporating global health courses into already existing degree programs, such as medical degrees. In addition, by offering certificate programs in global health, students could pursue training in global health without participating in a full public health degree program. Universities that already offer general public health degrees should add core courses in global health to afford the opportunity for their students to broaden their training into global health.

Second, we also found that very few programs in our study offered undergraduate courses in global health. We encourage universities to offer more global health courses that undergraduate students can join. Exposing undergraduates to global health courses may help spark students' interest in global health early in their academic careers and encourage them to pursue graduate training in this field. At the University of Southern California, there has been substantial demand from undergraduates for global health courses and opportunities over the last five years. Similarly, in other institutions, the introduction of global health as part of the undergraduate medical training is beginning to emerge, although it is likely to face challenges in terms of perceived relevance by pre-clinical and clinical students and program overload. We suggest that global health problems represent a superb platform for teaching interdisciplinarity.

While globalization has brought challenges for health, it has also brought new ways to collaborate in education. New, more flexible models of learning should be embraced, such as distance learning and experiential learning opportunities [5]. These can provide another way that universities can offer a wider range of global health courses without additional expenses. Curricular materials can be shared; lectures can be webcast globally; and multi-institutional research is increasingly feasible. Universities can take advantage of online courses offered for free, such as those offered by The Johns Hopkins Bloomberg School of Public Health or the Consortium of Universities for Global Health (CUGH). Faculty from two APRU member universities in the United States (the University of California at Irvine and the University of Southern California) developed an online course in global health leadership in which five universities from around the Pacific Rim participated. Students can also be encouraged to enroll in massive open online courses (MOOC). However, careful attention must be paid to ensure that contact hours within these courses remain as high as in traditional fulltime programs and that quality instruction is maintained [6, 24, 28-31].

Third, there is a growing recognition that improving the health of populations across the globe will require a multi-faceted, multi-disciplinary approach, as highlighted in the literature $[1,4,5,21,22,24]$. The factors which determine health status are complex and global health training requires an understanding of the multitude of determinants of health, such as social, economic, political and demographic factors. Preparing a global health workforce with expertise in an array of disciplines and contexts can help address global health challenges. Training of more than just medical doctors or epidemiologists will be required to meet these challenges. As the world becomes increasingly globalized through international travel and commerce, it is necessary to think about health in a global context. Improving global health can support national, regional and global security interests by fostering political stability, diplomacy, and economic growth worldwide. Experts in trade, migration, security and governance can help promote health globally. Solutions to combat the rise in non-communicable diseases and the influence of the environment in health status require the application of theories and knowledge from multiple fields. The research capabilities and surveillance required to combat pressing global health problems require significant capacity at many levels, including governmental, research and clinical. In addition, the ability of universities to conduct research requires the existence of capable Institutional Review Boards (also called Research Ethics Committees) that possess an advanced level of public health ethics, research methods, as well as knowledge from many other disciplines, in order to protect human subjects involved in research within the country, as well as outside. Diversity within schools in terms of programs and disciplines can promote training at many levels.

Universities are encouraged to involve faculty from different departments and disciplines in providing global health education. Courses from a variety of disciplines should be offered, such as courses in medical anthropology, health economics, environmental health, psychology, demography, big data and health informatics, business and leadership, and global health diplomacy. In addition, the role of cultural beliefs and practices in health outcomes is well-acknowledged and calls for 
training in qualitative methods. A major gap in many students' training is the absence of qualitative research methods courses, especially among medical students.

Fourth, our results corroborate those of Frenk et al. and others' in showing that the current financial investment in professional education is insufficient to meet the growing demand in global health [7, 24]. Engaging all stakeholders in global health education and training is needed in order to adequately fund professional education in the field and train the multi-disciplinary workforce required to address current global health priorities and to help foster health equity around the globe.

Increased global health training opportunities for students and faculty should be considered a priority. Short-term fellowship and training programs are available for faculty in developing economies to spend time in a developed country, such as the Fulbright Training Program, U.S. National Institutes of Health or programs funded by governments, such as Japan, These programs can provide training opportunities that do not require local university support. Such programs contribute to sharing of unique experiences and expertise from both developing and developed nations, benefitting both parties and can often lead to additional research collaborations.

Increased funding of international field placement opportunities will allow more students to gain valuable global health experience first-hand. Universities should provide competitive scholarships and placement assistance for students who want to do well-planned fieldwork abroad. While universities struggle with budget constraints that often make these programs cost-prohibitive, we feel global health practicums are a vital part of global health education and training. The value of international global health practicum opportunities as been welldocumented in the literature; through such experiences students can gain crucial exposure, empathy and witness first-hand how public health works in the real world including cultural competency and language skills, increased awareness regarding health challenges in resource-constrained health systems and greater selfconfidence [28, 32, 33].

In addition, financial support to cover travel costs to global health conferences may also be an important way to expose students and faculty to global health research being conducted around the globe and to meet others doing similar work. Extramural conference funding opportunities, such as conference travel grants, are also often available. Offering free global health symposiums and conferences at universities for local students and faculty might also facilitate increased interest and exposure to global health research, as well as promote networking opportunities.

\section{Conclusions}

The discipline of global health is increasingly recognized as making an important contribution to achieving greater health equity and improving health outcomes globally. Many economies in the Pacific Rim share overlapping health challenges, concerns and goals. Instructional and institutional changes are needed to meet the growing demand for trained global health professionals from a range of disciplines. Pacific Rim universities need to develop and expand global health educational opportunities to meet the upcoming challenges in providing global health education. Training a competent global health workforce will not only help to reduce the current global burden of disease in the Pacific Rim and build capacity to tackle current and emerging health threats, but can be expected to set long-term global health priorities and influence policy on a global scale.

\section{Endnotes}

${ }^{1}$ Johns Hopkins and Hanoi School of Public Health are not APRU members. However, they have cooperated for many years in the APRU Global Health Program as nonmember universities.

\section{Acknowledgements \\ We would like to thank the members of the Association of Pacific Rim Universities Global Health Program for their participation in this study.}

\section{Authors' contributions}

HW, CT and JS conceived of the study, and participated in its design and coordination and MW helped to draft the manuscript. DP conducted the study and analysed the data. MW, CC, JM, and MJ participated in the data collection and writing of the manuscript. All authors read and approved the final manuscript.

\section{Competing interests}

The authors declare that they have no competing interests.

\section{Author details}

${ }^{1}$ Department of Preventive Medicine, University of Southern California, Keck School of Medicine, 2001 N Soto Street SSB 318G, Los Angeles, CA 90064, USA. ${ }^{2}$ School of Population Health, University of Auckland, Auckland, New Zealand. ${ }^{3}$ National Taiwan University (NTU) College of Public Health, Global Health Center, Taipei City, Chinese Taipei. ${ }^{4}$ Department of Community and Global Health, University of Tokyo, Graduate School of Medicine, Tokyo, Japan. ${ }^{5}$ Association of Pacific Rim Universities, Hong Kong, Hong Kong SAR.

Received: 10 June 2015 Accepted: 9 May 2016

Published online: 23 June 2016

\footnotetext{
References

1. Fineberg HV, Hunter DJ. A global view of health - an unfolding series. N Engl J Med. 2013;368(1):78-9.

2. Ackerly DC, Udayakumar K, Taber R, Merson MH, Dzau VJ. Perspective: global medicine: opportunities and challenges for academic health science systems. Acad Med. 2011;86(9):1093-9.

3. Fried LP, Bentley ME, Buekens P, Burke DS, Frenk JJ, Klag MJ, et al. Global health is public health. Lancet. 2010;375(9714):535-7.

4. Quinn TC. The Johns Hopkins Center for Global Health: transcending borders for world health. Acad Med. 2008:83(2):134-42

5. Fried LP, Piot P, Frenk JJ, Flahault A, Parker R. Global public health leadership for the twenty-first century: towards improved health of all populations. Global Public Health. 2012;7(S1):S5-15.
} 
6. Evans D. The role of schools of public health: learning from history, looking to the future. J Public Health. 2009;31 (3):446-50.

7. Frenk J, Chen L, Bhutta ZA, Cohen J, Crisp N, Evans T, Fineberg H, Garcia P, Ke Y, Kelley P, Kistnasamy B, Meleis A, Naylor D, Pablos-Mendez A, Reddy S, Scrimshaw S, Sepulveda J, Serwadda D, Zurayk H. Health professionals for a new century: transforming education to strengthen health systems in an interdependent world. Lancet. 2010;376:1923-58.

8. Birbeck GL, Wiysonge CS, Mills EJ, Frenk JJ, Zhou XN, Jha P. Global health: the importance of evidence-based medicine. BMC Med. 2013;11:223.

9. Koplan JP, Bond TC, Merson MH, for the Consortium of Universities for Global Health Executive Board, et al. Towards a common defi nition of global health. Lancet. 2009;373:1993-5.

10. Griffiths S, Tiang JL, Yeoh EK, editors. Routledge Handbook of Global Public Health in Asia. New York: Routledge Handbooks; 2014.

11. Babich LP, Bicknell WJ, Culpepper L, Jack BW. Social responsibility, international development, and institutional commitment: lessons from the Boston University experience. Acad Med. 2008;83(2):143-7.

12. Haq C, Baumann L, Olsen CW, Brown LD, Kraus C, Bousquet G, et al. Creating a center for global health at the University of Wisconsin-Madison. Acad Med. 2008;83(2):148-53.

13. Koplan JP, Baggett RL. The Emory Global Health Institute: developing partnerships to improve health through research, training, and service. Acad Med. 2008;83(2):128-33.

14. Lorntz B, Boissevain JR, Dillingham R, Kelly J, Ballard A, Scheld WM, et al. A trans-university center for global health. Acad Med. 2008;83(2):165-72.

15. Macfarlane SB, Agabian N, Novotny TE, Rutherford GW, Stewart CC, Debas HT. Think globally, act locally, and collaborate internationally: global health sciences at the University of California, San Francisco. Acad Med. 2008;83(2):173-9.

16. McKinley DW, Williams SR, Norcini JJ, Anderson MB. International exchange programs and U.S. medical schools. Acad Med. 2008:83(10 Suppl):S53-7.

17. Saba N, Brewer TF. Beyond borders: building global health programs at McGill University Faculty of Medicine. Acad Med. 2008;83(2):185-91.

18. Vermund SH, Sahasrabuddhe W, Khedkar S, Jia Y, Etherington C, Vergara A. Building global health through a center-without-walls: the Vanderbilt Institute for Global Health. Acad Med. 2008;83(2):154-64.

19. Williams RS, Casey PJ, Kamei RK, Buckley EG, Soo KC, Merson MH, et al. A global partnership in medical education between Duke University and the National University of Singapore. Acad Med. 2008;83(2):122-7.

20. Debas HT, Coates TJ. The University of California Global Health Institute opportunities and challenges. Infect Dis Clin North Am. 2011;25(3):499-509. vii.

21. Farquhar C, Nathanson N, Consortium Working G. The Afya Bora Consortium: an Africa-US partnership to train leaders in global health. Infect Dis Clin North Am. 2011;25(2):399-409.

22. Patrick WK. The Asia Pacific Academic Consortium for Global Public Health and Medicine: stabilizing south-south academic collaboration. Infect Dis Clin North Am. 2011;25(3):537-54. viii.

23. Merson MH. University engagement in global health. N Engl J Med. 2014; 1;370(18):1676-8

24. Drain PK, Primack A, Hunt D, Fawzi WW, Holmes K, Gardner P. Global health in medical education: a call for more training and opportunities. Acad Med. 2007;82(3):226-30.

25. Crump JA, Sugarman J, the Working Group on Ethics Guidelines for Global Health Training (WEIGHT). Ethics and best practice guidelines for training experiences in global health. Am J Trop Med Hyg. 2010;83(6):1178-82.

26. Lencucha R, Mohindra K. A snapsot of global health education at North American universities. Glob Health Promot. 2014;21(1):63-7.

27. Merson MH, Chapman Page K. The dramatic expansion of university engagement in global health: Implications for U.S. Policy. A report of the CSIS Global Health Policy Center. 2009. Accessed on 22 Nov 2015 at: http://csis.org/files/media/csis/pubs/090420_merson_dramaticexpansion.pdf

28. Jeffrey J, Dumont RA, Kim GY, Kuo T. Effects of international health electives on medical student learning and career choice: results of a systematic literature review. Fam Med. 2011;43(1):21-8.

29. Cuff P, Schmitt M, Zierler B, Cox M, De Maeseneer J, Maine LL, Reeves S, Spencer HC, and Thibault GE. Interprofessional education for collaborative practice: views from a global forum workshop. J Interprof Care. 2013;28(1):1-3.

30. Mayadas AF, Bourne J, Bacsich P. Online education today. Science. 2009;323:85-9.
31. Karunathilake IM, Liyanage CK. Accreditation of public health education in the Asia-Pacific region. Asia Pac J Public Health. 2015;27(1):38-44.

32. Sykes KJ. Short-term medical service trips: a systematic review of the evidence. Am J Public Health. 2014;104:e38-48.

33. Thompson M, Huntington M, Hunt D, Pinsky L, Brodie J. Educational effects of international health electives on US and Canadian medical students and residents: a literature review. Acad Med. 2003;78(3):342-7.

\section{Submit your next manuscript to BioMed Central and we will help you at every step:}

- We accept pre-submission inquiries

- Our selector tool helps you to find the most relevant journal

- We provide round the clock customer support

- Convenient online submission

- Thorough peer review

- Inclusion in PubMed and all major indexing services

- Maximum visibility for your research

Submit your manuscript at www.biomedcentral.com/submit
Biomed Central 